\title{
ANALISIS PETA POTENSI RAWAN KEMACETAN BERBASIS GEOGRAPHY INFORMATION SYSTEM DI KOTA MEDAN
}

\author{
Dadang Hartanto \\ Program Studi Administrasi Publik, Fakultas Ilmu Sosial dan Ilmu Politik, UMSU \\ Jl. Kapten Mukhtar Basri No. 3 Medan, Sumatera Utara \\ e-mail: dadanghartanto@umsu.ac.id
}

\begin{abstract}
Abstrak
Pertambahan penduduk setiap tahunnya mengalami kenaikan akibat adanya pergerakan. Sehingga, berimplikasi terhadap kebutuhan transportasi. Perkembangan lonjakan ekonomi yang kian tinggi juga berdampak pada pertambahan angka kendaraan yang signifikan. Dampaknya adalah kemacetan yang dapat mempengaruhi berbagai macam aktvitas masyarakat terutama pada pendapatan masyarakat, sehingga penting untuk mengkaji potensi daerah rawan kemacetan di Kota Medan berbasis Geography Information System (GIS). Metode penelitian yang digunakan adalah penelitian studi pustaka dan di dukung data-data sekunder untuk memperkuat analisis penelitian, kemudian dianalisis secara dekskriptif. Dari pemetaan daerah yang dilakukan, didapati bahwa tingginya angka kemacetan di Kota Medan disebabkan oleh kurangnya kesadaran masyarakat terhadap tertib lalu lintas. Selain itu, juga didapati keluar masuknya anak sekolah, masyarakat yang tidak patuh pada aturan parkir kendaraan serta titik rawan kemacetan lainnya terdapat pada lintasan kereta api.
\end{abstract}

Kata kunci: Peta, Potensi Kemacetan, GIS

\begin{abstract}
Population growth increases every year due to movement. Thus, it has implications for transportation needs. The development of an increasingly high economic boom also had an impact on the significant increase in vehicle numbers. The impact is congestion that can affect various kinds of community activities, especially on community income, so it is important to examine the potential for congestion-prone areas in Medan based on the Geography Information System (GIS). The research method used is literature study and supported by secondary data to strengthen research analysis, then analyzed descriptively. From the mapping of the area carried out, it was found that the high number of congestion in the city of Medan was caused by the lack of public awareness of the orderly traffic. In addition, also found the entry and exit of school children, people who do not comply with vehicle parking rules and other congestion-prone points are found on the train track.
\end{abstract}

Key words: Map, Potential Congestion, GIS

\section{PENDAHULUAN}

Laju pertumbuhan penduduk Sumatera Utara yang semakin meningkat setiap tahunnya menimbulkan dampak krusial di berbagai wilayah perkotaan. Menurut data Badan Pusat Statistik (BPS) pada tahun 2020 angka laju pertumbuhan penduduk (LPP) pada wilayah perkotaan saat ini sudah mencapai 2,01 persen setiap tahunnya yaitu sebesar 5.630.000 jiwa.

Tentu dengan laju pertumbuhan tersebut menyebabkan terkonsentrasinya 
penduduk di wilayah perkotaan dengan adanya fenomena pergerakan penduduk. Wilayah perkotaan menjadi idaman setiap masyarakat desa. Sehingga berbagai faktor dan pendorong terjadi, seperti dorongan ekonomi, tingkat upah yang tinggi upah dan menjanjikan.

Semakin bertambahnya jumlah penduduk tentu seiring dengan mobilitas yang tinggi, sebab setiap penduduk membutuhkan akses transportasi untuk efisiensi waktu dan efektifitas dalam bekerja. Kebutuhan akan tranportasi bagian dari komponen utama dalam peningkatan arus perekonomian dalam upaya mengoptimalkan potensi daerah yang selama ini dimiliki. Namun juga untuk membuka sektor-sektor ekonomi baru untuk memajukan sebuah daerah (Mangatur, 2018).

Guna memanfaatkan dan membuka potensi- potensi perekonomian yang baru maka keikutsertaan pemerintah dalam mengatur pengalokasian belanjanya penting untuk terus dioptimalkan. Oleh sebab itu kebutuhan untuk transportasi semakin meningkat setiap tahunnya. Dalam teori ekonomi dijelaskan jika permintaan bertambah maka persediaan juga meningkat.

Analogi tersebut dalam konteks bertambahnya jumlah penduduk ibarat konsumen dan kebutuhan transportasi merupakan akses transportasi merupakan persediaan kendaraan (Munazar, 2018). Namun, dengan permintaan kendaraan yang meningkat menambah permasalahan baru lagi yaitu kemacetan misalnya di Kota Medan yang terus mengalami kemacetan di beberapa titik pada level tinggi. Titik kemacetan Kota Medan tersebar $60 \%$ di jalan kota, baik pusat kota maupun jalan penghubung Kota Medan.

Sedangkan selebihnya merupakan jalan lintas menuju luar daerah yang ada di Sumatera Utara. Menurut data didapati dari jumlah kendaraan mencapai 2,7 juta unit dan sudah melampaui jumlah penduduk yaitu sebesar 2,2 juta jiwa (BPS, 2018), oleh sebab itu jumlah penduduk tidak sebanding dengan besarnya jumlah kendaraan.

Selanjutnya didasari data (BPS, 2015) secar fisik panjang jalan Kota Medan sebesar 3.191,50 Km. dengan klasifikasi 4,41 persen jalan Negara, 1,05 persen jalan provinsi; dan 94,54 persen jalan kabupaten/kota. Angka tersebut telah termasuk kategori $207 \mathrm{Km}$ jalan yang mengalami kerusakan, baik kerusakan ringan maupun kerusakan berat. Walaupun demikian, sejumlah ruas jalan sudah diperbaiki dan dengan adanya padat pembangunan jalan tol yang menghubungkan Kota Medan.

Sehingga memungkinkan bagi masyarakat untuk memilih jalan atau alat transportasi yang dibangun oleh pemerintah. Pesatnya pertumbuhan ekonomi yang kian meningkat terutama ada wilayah Medan, Binjai dan Deli Serdang berpengaruh terhadap kenaikan jumlah kendaraan yang signifikan. Pergerakan penduduk dan barang, menyebabakan kemacetan lalu lintas dan menyebabkan biaya sosial yan tinggi misalnya durasi waktu tempuh perjalanan, kebutuhan bahan bakar sampai pada meningkatnya jumlahkecelakaan dan stres di kalangan masyarakat.

Pada dasarnya permasalahan kemacetan di Kota Medan menjadi tugas bersama khususnya masyarakat Kota Medan. Mengapa demikian, karena jika dikaji dari perspektif budaya, kemacetan terjadi karena kurangnya kesadaran oleh masyarakat serta sikap apatis yang tinggi. Pola pikir yang sempit dan bertumpu pada petugas kepolisian dan dinas lalu lintas bukan menjadi solusi mengatasi kemacetan, tetapi kata kuncinya adalah kesadaran.

Masyarakat yang heterogen, budaya yang mejemuk menjadikan Kota Medan identik dengan watak keras. Oleh sebab itu, sudah menjadi kewajiban masyarakat untuk mengendalikannya. Disisi lain, kemacetan akan berdampak pada meningkatnya pencemaran udara sebab pada kecepatan rendah konsumsi 
energi lebih tinggi. Kemacetan juga dapat mempengaruhi berbagai macam aktvitas masyarakat karena disamping berdampak pada kelancaran aktivitas masyarakat dan yang tidak kalah pentingnya berdampak terhadap pendapatan masyarakat.

Banyaknya waktu yang terbuang akibat dari kemacetan berpengaruh pada menurunnya kesempatan untuk mendapatkan pendapatan masyarakat dan mengakibatkan aksesibilitas jalan terhambat. Menyikapi permasalahan diatas tentu masyarakat menginginkan solusi dari kemacetan.

Sejauh ini regulasi dan penganggulangan kemacetan oleh aparat dan pemerintah sudah baik, namun masih perlu ditingkatkan. Misalnya bekerjasama dengan kepolisian, dinas lalu lintas, masyarakat dan tokoh- tokoh sebagai upaya membangun kesadaran masyarakat dari persepektif kultural. Sedangkan dari perspektif teknis masyarakat perlu dihidangkan dengan pemetaan daerahdaerah rawan kemacetan sebagai upaya meminimalisir tingkat kemacetan di Medan agar tidak terkonsentrasi di satu titik yaitu dengan penyajian peta rawan kemacetan.

Kondisi tersebut mendorong peneliti untuk melakukan penelitian tentang analisis peta rawan kemacetan menggunakan Geography Information System (ArcGIS). Menurut ICA (International Cartography Association) peta merupakan penggambaran simbolis yang menekankan hubungan antara elemen ruang tertentu, seperti objek, wilayah, atau tema. Orientasi peta merupakan korelasi antara arah pada peta dan arah kompas yang sesuai dalam kenyataan (Cartwright, 2015).

Banyak peta yang statis, tetap pada kertas atau media tahan lama lainnya, sementara yang lain bersifat dinamis atau interaktif. Namun demikian, yang umum dipakai untuk menggambarkan peta harus dapat mewakili ruang apa pun, nyata atau fiksi, dengan memperhatikan konteks atau skala.
Ruang yang dipetakan mungkin dua dimensi, misalnya relief bumi, tiga dimensi, seperti interior bumi, atau bahkan lebih banyak ruang abstrak dari dimensi apa pun, seperti muncul dalam fenomena pemodelan yang memiliki banyak variabel independen. Selanjutnya dijelaskan oleh (Vesilev, 2007) bahwa konten peta dibagi dalam tiga kelompok: bidang peta adalah model matematika dari bagian yang diwakili dari kenyataan, memiliki beberapa sifat: skala; sistem koordinasi bidang dan ketinggian; permukaan referensi; proyeksi kartografi; ukuran fisik. Terlihat bahwa kerangka referensi posisi, kontur, dan garis koordinat adalah komponen dari bidang peta. Bidang peta ditentukan secara ketat oleh a) bingkai pada peta atau b) berdasarkan batas objek peta.

Komponen internal adalah tandatanda kartografis yang mewakili objek pasti dari kenyataan. Mereka terletak di bidang peta dan mereka mendapatkan lokasi spesifik mereka sendiri. Lokasi ini menghubungkan nyanyian dengan bendabenda mereka. Komponen internal telah menerima properti dari bidang peta, khususnya skala dan sistem koordinatnya.

Di luar lapangan, komponen internal adalah bentuk geometris, piktogram, gambar, dan sebagainya. Ketika mereka diposisikan di bidang peta di lokasi tertentu, mereka mendapatkan properti bidang dan menjadi tanda-tanda kartografis. Komponen eksternal telah ditandai objek peta; bidang peta dan peta itu sendiri.

Mereka adalah kendaraan tanda, tertulis atau grafis, tetapi mereka bukan tanda-tanda kartografi karena mereka tidak terhubung ke bidang peta. Berbagai jenis peta dapat memiliki berbagai komponen eksternal, tetapi komponen internal yang paling penting adalah legenda peta, judul peta, spesifikasi interval kontur, dan representasi skala. Peta yang dapat digunakan harus terdiri dari setidaknya satu elemen dari setiap komponen. 
Peta diolah menggunakan software yang dinamakan ArcGIS dan hasilnya sebagai informasi yang dapat disajikan kepada masyarakat atau publik berupa peta tematik/umum yang sering disebut sebagai Geography Information System (GIS). GIS memiliki fungsi sistem yaitu menangkap, menyimpan, memanipulasi, menganalisis, mengelola, dan menyajikan data spasial atau geografis.

Aplikasi GIS adalah alat yang memungkinkan pengguna untuk membuat kueri interaktif (pencarian yang dibuat pengguna), menganalisis informasi spasial, mengedit data dalam peta, dan menyajikan hasil dari semua operasi. GIS dapat merujuk ke sejumlah teknologi, proses, teknik, dan metode yang berbeda. Hal itu melekat pada banyak operasi dan memiliki banyak aplikasi yang berkaitan dengan teknik, perencanaan, manajemen, transportasi, logistik, asuransi, telekomuni kasi, dan bisnis. Untuk alasan itu, GIS dan aplikasi intelijen lokasi dapat menjadi dasar bagi banyak layanan berbasis lokasi yang mengandalkan analisis dan visualisasi.

GIS bisa menghubungkan informasi yang tidak terkait dengan menggunakan lokasi sebagai variabel indeks utama. Lokasi atau luasan dalam ruang-Bumi waktu dapat dicatat sebagai tanggal / waktu kejadian, dan koordinat $\mathrm{x}, \mathrm{y}$, dan $\mathrm{z}$ yang mewakili, bujur, lintang, dan ketinggian, masing-masing. Semua referensi spasial-temporal dan perluasan lokasi Bumi harus saling terkait, pada akhirnya ke lokasi atau tingkat fisik nyata. Karakteristik utama GIS ini telah mulai membuka jalan baru untuk penyelidikan ilmiah.

\section{METODE PENELITIAN}

Berdasarkan uraian permasalahan di latarblekang sebelumnya maka untuk pelaksanaan penelitian ini dilakukan menggunakan Studi Kepustakaan (library research). Penelitian ini didasarkan pada proses dan pengumpulan data-data pustaka, membaca dan mencatat serta mengolah bahan penelitian berupa jurnal, artikel dan buku- buku yang berkaitan dengan topik penelitian. Kemudian dijelaskan oleh (Sugiyono, 2010) penelitian pustaka merupakan proses memecahkan masalah-masalah aktual sekarang ini dan mengumpulkan data atau informasi untuk disusun, dijelaskan dan dianalisis dengan mamakai sumber perpustakaan.

Peneliti memakai metode analisis deskriptif yang menekankan pada kekuatan sumber-sumber dan data-data yang ada dengan mengandalkan teoriteori dan konsep konsep selanjutnya diinterpretasikan termasuk menggunakan peta sebagai dasar analisis.

Sumber-sumber yang dimaksud dari karya ilmiah berupa jurnal nasional maupun internasional yang di publikasi oleh para intelektual, ahli dan kompeten tentang pemetaan. Lokasi penelitian berada di Kota Medan dengan melakukan pemetaan di semua kecamatan dan meneliti jalan-jalan yang menjadi titik rawan kemacetan. Pertimbangannya adalah dari segi kemenarikan dan kenyataan permasalahan.

Data yang diperlukan berupa data tentang tingkat kemcatan dan data jumlah kendaraan di Kota Medan. Sumber data penelitian ini adalah karya ilmiah berupa jurnal, peta administrasi yang didapatkan dari Badan Informasi Geospasial (BIG). Teknik pengumpulan data dengan dokumentasi, mengidentifikasi wacana dari buku- buku, makalah atau artikel, majalah, jurnal, koran, internet, ataupun informasi lainnya yang berhubungan dengan judul penelitian ini untuk mencari hal-hal atau variabel yang berupa catatan, transkip, buku, dan sebagainya yang mempunyai keterkaitan dengan kajian kemacetan. Selanjutnya dilakukan analisis untuk mendapatkan konklusi. Data yang terkumpul berupa angka, kata-kata dan gambar disebabkan adanya penerapan metode kualitatif. Disamping itu, semua yang terkumpul menjadi kunci terhadap apa yang sudah diteliti. 


\section{HASIL DAN PEMBAHASAN}

Dari pemaparan latarbelakang masalah dan metode yang digubnakan dalam penelitian ini, maka dapat diuraikan secara jelas permasahan tingginya level kemacetan di beberapa titik di Kota Medan.

\section{Gambaran Umum Kota Medan}

Sebagian besar wilayah Kota Medan merupakan dataran rendah yang merupakan tempat pertemuan dua sungai penting, yaitu Sungai Babura dan Sungai Deli. Secara geografis terletak antara $3^{\circ} .27^{\prime}$ - $3^{\circ} .47^{\prime}$ Lintang Utara dan $98^{\circ} .35^{\prime}-98^{\circ} .44^{\prime}$ Bujur Timur dengan ketinggian 2,5 - 37,5 meter di atas permukaan laut dan berbatasan Kabupaten Deli Serdang di sebelah Utara, Selatan, Barat dan Timur.

Geologi Kota Medan merupakan salah satu dari 33 Daerah Tingkat II di Sumatera Utara dengan luas daerah sekitar 265,10 km². Kota ini merupakan pusat pemerintahan Daerah Tingkat I Sumatera Utara yang berbatasan langsung dengan Kabupaten Deli Serdang Kota Medan mempunyai iklim tropis dengan suhu minimum menurut Stasiun BMKG Medan pada tahun 2018 yaitu 23,30C dan suhu maksimum yaitu $34,30 \mathrm{C}$ serta menurut Stasiun Sampali suhu minimumnya yaitu $23,10 \mathrm{C}$ dan suhu maksimum yaitu 33,70C.

Kelembaban udara di wilayah Kota Medan rata-rata 78 - 85\%, dan kecepatan angin rata-rata sebesar $2,4 \mathrm{~m} / \mathrm{sec}$, sedangkan rata-rata total laju penguapan tiap bulannya 108,2 mm. Hari hujan di Kota Medan pada tahun 2018 per bulan 14 hari dengan rata-rata curah hujan menurut Stasiun Sampali per bulannya $179 \mathrm{~mm}$. Adapun luas wilayah kota Medan Sebagai berikut:

Tabel. 1 Luas Wilayah Kota Medan Menurut Kecamatan Tahun 2018

\begin{tabular}{llcc}
\hline No. & Nama Kecamatan & Luas Wilayah & Persentase \\
\hline 1. & Medan Tuntungan & 20,8 & 7,80 \\
2. & Medan Johor & 14,58 & 5,50 \\
3. & Medan Amplas & 11,19 & 4,22 \\
4. & Medan Denai & 9,05 & 3,41 \\
5. & Medan Area & 5,52 & 2,08 \\
6. & Medan Kota & 5,27 & 1,99 \\
7. & Medan Maimun & 2,98 & 1,13 \\
8. & Medan Polonia & 9,01 & 3,40 \\
9. & Medan Baru & 5,84 & 2,20 \\
10. & Medan Selayang & 12,81 & 4,83 \\
11. & Medan Sunggal & 15,44 & 5,83 \\
12. & Medan Helvetia & 13,16 & 4,97 \\
13. & Medan Petisah & 6,82 & 2,57 \\
14. & Medan Barat & 5,33 & 2,01 \\
15. & Medan Timur & 7,76 & 2,93 \\
16. & Medan Perjuangan & 4,09 & 1,54 \\
17. & Medan Tembung & 7,99 & 3,01 \\
18. & Medan Deli & 20,84 & 7,86 \\
19. Medan Labuhan & 36,67 & 13,83 \\
20. & Medan Marelan & 23,82 & 8,99 \\
21. & Medan Belawan & 26,25 & 9,90 \\
\hline
\end{tabular}

Sumber: BPS, 2018 
Berdasarkan data tabel 1 diatas menunjukkan bahwa terdapat perbedaan luas wilayah masing-masing kecamatan di Kota Medan. Kecamatan yang memiliki wilayah paling luas adalah Medan Labuhan, sedangkan Kecamatan yang memiliki luas wilayah paling kecil adalah Medan Maimun, Medan Kota, Medan Timur dan Medan Baru. Ini mengindikasikan bahwa tingkat kemacetan juga bisa terjadi karena luas wilayah yang sempit tidak sebanding dengan jumlah penduduk yang tinggal di wilayah perkotaan, sehingga menyebabkan kepadatan penduduk. Oleh sebab itu agar tidak terjadi ketidak seimbangan tersebut perlu dilakukan sebuah langkah-langkah kebijakan dan regulasi yang mengatur pergerakan penduduk di Kota Medan agar tidak semua titik/ruas jalan terjadi kemacetan. Untuk lebih jelasnya luas wilayah Kecamatan di Kota Medan dapat dilihat pada Gambar 1 berikut ini.

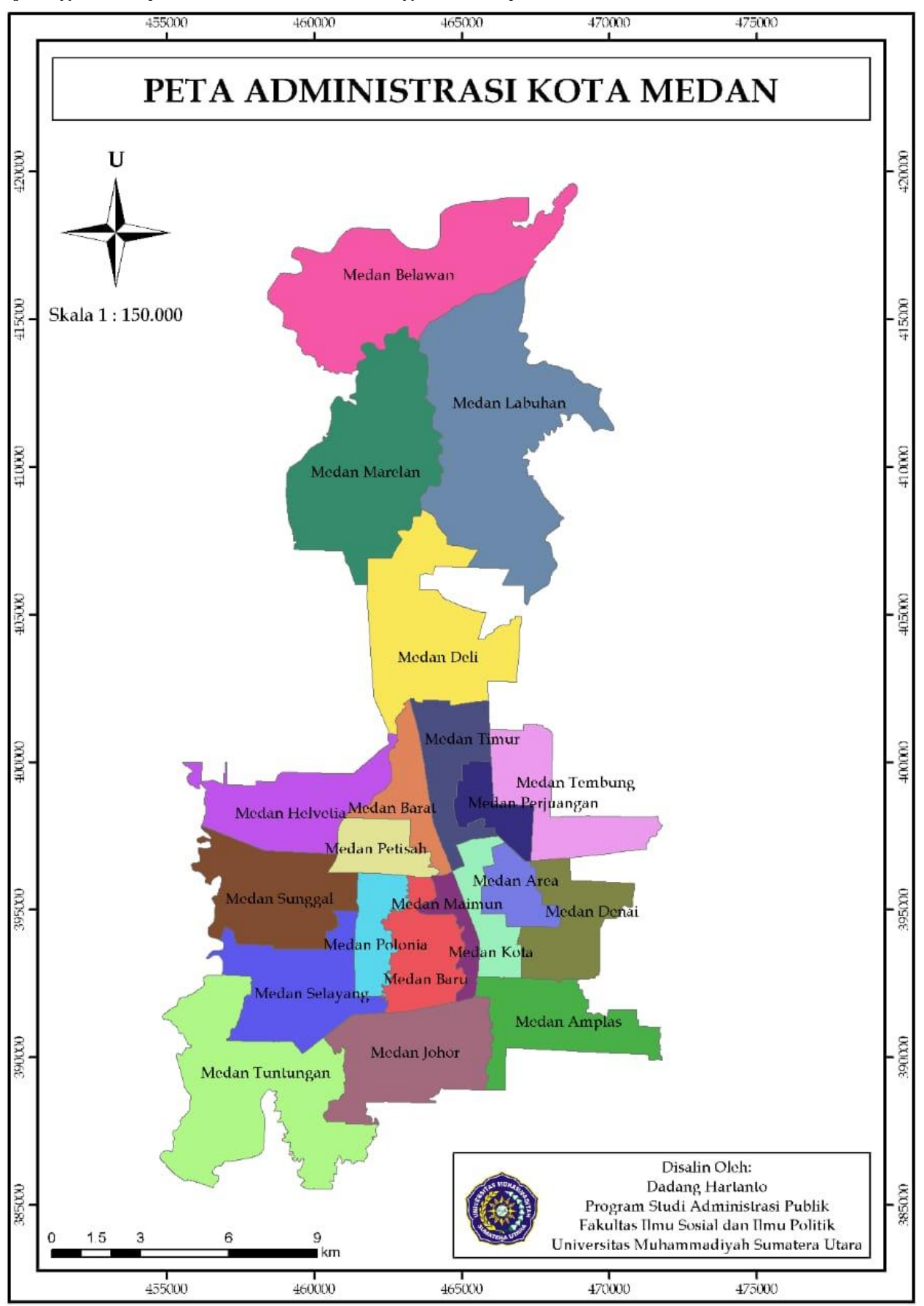

Gambar 1. Peta Wilayah Administrasi Kota Medan 


\section{Kondisi Jalan Kota Medan}

Prasarana jalan merupakan urat nadi kelancaran lalu lintas di darat. Lancarnya arus lalu lintas akan sangat menunjang perkembangan ekonomi suatu daerah. Guna menunjang kelancaran perhubungan darat di Kota Medan sampai dengan keadaan akhir tahun 2017 tercatat panjang jalan yaitu $3.191,50 \mathrm{~km}$.
Sarana jalan yang ada pada tahun 2017 tercatat $2.984,5 \mathrm{~km}$ dalam kondisi baik $15,80 \mathrm{~km}$ sedang dan 20,10 km rusak, sedangkan yang dalam kondisi rusak berat $171,10 \mathrm{~km}$ dan yang tidak terperinci 0,00 km. (BPS, 2018). Secara rinci dapat dilihat pada tabel berikut ini:

Tabel 2. Panjang Jalan Menurut Kecamatan

\begin{tabular}{llcccc}
\hline No. & Nama Kecamatan & Negara & Provinsi & Kabupaten & Jumlah \\
\hline 1. & Medan Tuntungan & 9,0 & - & 172,1 & 181,1 \\
2. & Medan Johor & 11,0 & 5,3 & 183,4 & 199,7 \\
3. & Medan Amplas & 7,8 & - & 159,6 & 167,4 \\
4. & Medan Denai & - & 0,8 & 166,3 & 167,1 \\
5. & Medan Area & 0,8 & 2,3 & 103,7 & 106,8 \\
6. & Medan Kota & 5,7 & 2,7 & 123,4 & 131,8 \\
7. & Medan Maimun & 5,6 & 4,9 & 38,3 & 48,8 \\
8. & Medan Polonia & 2,5 & - & 100,1 & 102,6 \\
9. & Medan Baru & 7,0 & - & 102,3 & 109,3 \\
10. & Medan Selayang & 12,4 & - & 155,4 & 167,8 \\
11. & Medan Sunggal & 24,3 & - & 174,7 & 199,0 \\
12. & Medan Helvetia & 8,0 & 2,8 & 202,4 & 213,2 \\
13. & Medan Petisah & 5,6 & - & 105,2 & 110,8 \\
14. & Medan Barat & 9,0 & 0,7 & 101,7 & 111,4 \\
15. & Medan Timur & 5,5 & 0,7 & 173 & 179,2 \\
16. & Medan Perjuangan & - & - & 103,2 & 103,2 \\
17. & Medan Tembung & 4,1 & 5,1 & 140,9 & 150,1 \\
18. & Medan Deli & 8,1 & 6,9 & 241,7 & 256,7 \\
19. Medan Labuhan & 10,2 & - & 192,8 & 203 \\
20. & Medan Marelan & - & 1,2 & 126,4 & 127,6 \\
21. & Medan Belawan & 4,1 & - & 150,8 & 154,9 \\
\hline
\end{tabular}

Sumber: BPS, 2018

\section{Pemetaan Potensi Kemacetan}

Di Kota Medan fenomena kemacetan menyebabkan tersendatnya atau bahkan terhentinya lalu lintas yang disebabkan oleh banyaknya jumlah kendaraan melebihi kapasitas jalan. Kemacetan banyak terjadi terutama karena kurangnya moda transportasi publik atau system lalu lintas yang kurang baik atau memadai ataupun juga tidak seimbangnya kebutuhan jalan dengan kepadatan penduduk. Kemacetan lalu lintas menjadi permasalahan sehari-hari ditemukan di Pasar, Sekolah, Terminal bus, stasiun (seperti kejadian angkot ngetem sembarangan, kebakaran di pemukiman, dan sebagainya), lampu merah dan persimpangan jalan raya maupun rel kereta api di atau perlintasan rel kereta api yang hampir setiap jalan memakan waktu cukup lama yang akhirnya terjadi penumpukan kendaraan. Ditambah lagi perkembangan dan pertumbuhan ekonomi yang semakin meningkat di Kawasan Metropolitan Mebidang terutama Kota Medan telah membuat peningkatan jumlah pergerakan orang dan barang yang signifikan. Mobilitas orang dan barang di wilayah Kota Medan terus meningkat dan salah 
satu dampak negatifnya adalah terjadinya peningkatan kemacetan lalu lintas. Akibat dari kemacetan tersebut menimbulkan social cost yang cukup tinggi, lamanya waktu tempuh perjalanan, konsumsi bahan bakar menimbulkan biaya transportasi semakin tinggi hingga bertambahnya angka kecelakaan dan stres di tengah masyarakat (Susanti dan Magdalena, 2015). Namun demikian kondisi tersebut dapat diminimalisir dengan adanya sosialisasi kepolisian dan pemerintah terhadap kesadaran akan lalu lintas dan pilihan alternatif jalan sehubungan dengan sudah dilaksanakannya pembangunan infrastruktur berupa jalan tol. Salahsatu upaya sosialisasi telah dilakukan namun belum mampu mengatasi kemacetan. Hal tersebut tergambar dari data penelitian yang dilakukan penulis sebelumnya yaitu sebagai berikut:

Tabel 3. Jawaban Tentang Bentuk Keamanan dan Ketertiban Masyarakat Yang Sudah Terlaksana

\begin{tabular}{clcc}
\hline No. & \multicolumn{1}{c}{ Jawaban } & Jumlah & Persentase $(\%)$ \\
\hline 1. & Siskamling & 50 & $50 \%$ \\
2. & Gotong-royong & 30 & $30 \%$ \\
3. & Sadar lalu lintas & 10 & $10 \%$ \\
4. & Mediator konflik & 6 & $6 \%$ \\
5. & Lainnya & 4 & $4 \%$ \\
\hline & Total & 100 & $100 \%$ \\
\hline
\end{tabular}

Sumber, Hartanto 2018

Dari tabel 3 diatas dapat ditarik kesimpulan bahwa kategori jawaban siskamling menjadi kategori jawaban dengan persentase terbesar, dengan besaran 50 persen. Kategori jawaban lainnya menjadi kategori jawaban dengan persentase terkecil, dengan besaran 4 persen. Kategori jawaban mediator konflik dan sadar lalu lintas persentasenya cukup kecil, dengan besaran berturut-turut 6 dan 10 persen. Kategori jawaban gotong-royong menjadi kategori jawaban kedua terbesar dengan besaran 30 persen. Bentuk kamtibmas yang sudah terlaksana sendiri sebagian besar merupakan bentuk kamtibnas yang sudah menjadi tradisi di Indonesia terutama di daerah pedesaan dan perkampungan yaitu bentuk siskamling dan gotong-royong, sementara bentuk kamtibnas model baru seperti mediator konflik dan sadar lalu lintas belum banyak terlaksana. Tidak dapat di pungkiri kemacetan di sepanjang titik-titik tertentu banyak merugikan masyarakat. Adapun ruas-ruas jalan yang menjadi titik kemaceta di wilayah Kota Medan dapat dilihat pada Tabel 4 dan Gambar 2 berikut.

Tabel 4. Nama Jalan Titik Rawan Kemacetan

\begin{tabular}{|c|c|c|c|}
\hline No. & Nama Jalan & $\begin{array}{l}\text { Nama } \\
\text { Kecamatan }\end{array}$ & Penyebab \\
\hline 1. & Jl. Letda Sujono Simpang Jl. Padang & Percut Sei Tuan & Pool Bus dan Plaza Maju Bersama \\
\hline 2. & Jl. Kapten Muslim & Medan Helvetia & Pasar Sei Kambing \\
\hline 3. & $\begin{array}{l}\text { Jl. Pinag Baris, Jl. Setia Budi Simp. DR. } \\
\text { Mansyur } \\
\text { Shafiatulamaliyyah) }\end{array}$ & Medan Sunggal & $\begin{array}{l}\text { Pasar tumpah dan masuk keluar anak } \\
\text { sekolah }\end{array}$ \\
\hline 4. & $\begin{array}{l}\text { Jl. Jamin Ginting dan Jl. S. Parman } \\
\text { depan Perguruan Thomas }\end{array}$ & Medan Baru & Masuk dan keluar anak sekolah \\
\hline 5. & $\begin{array}{l}\text { Jl. MT. Hariyono, Jl. Sutomo dan Jl. P } \\
\text { Kemerdekaan depan perguruan } \\
\text { Methodist }\end{array}$ & Medan Timur & Masuk dan keluar anak sekolah \\
\hline
\end{tabular}




\begin{tabular}{|c|c|c|c|}
\hline 6. & Jl. A.R Hakim dan Jl. Thamrin Plaza & Medan Area & $\begin{array}{lll}\text { Adanya pasar } & \text { Sukarame dan } \\
\text { perlintasan } & \text { keretapi }\end{array}$ \\
\hline 7. & $\begin{array}{l}\text { Jl. S.M Raja depan terminal PMH dan } \\
\text { Simpang Amplas }\end{array}$ & Medan Amplas & $\begin{array}{l}\text { Adanya Pool Bus dan adanya terminal } \\
\text { liar (mobil plat hitam) }\end{array}$ \\
\hline \multirow[t]{7}{*}{8.} & Jl. Sutomo & Medan Kota & Parkir berlapis \\
\hline & Jl. M.T Haryono & & Motor dan bettor \\
\hline & Jl. S.M Raja Simpang Limun & & Adanya Pasar simpang Limun \\
\hline & Jl. S.M Raja depan PDAM Tirtanadi & & Perlintasan Keretapi \\
\hline & (Kedokteran UISU) & & Perlintasan Keretapi \\
\hline & Jl. Pandu & & \\
\hline & Jl. Imam Bonjol depan Yaspendhar & & Masuk keluar anak sekolah \\
\hline
\end{tabular}

Sumber: Hasil Penelitian, 2019

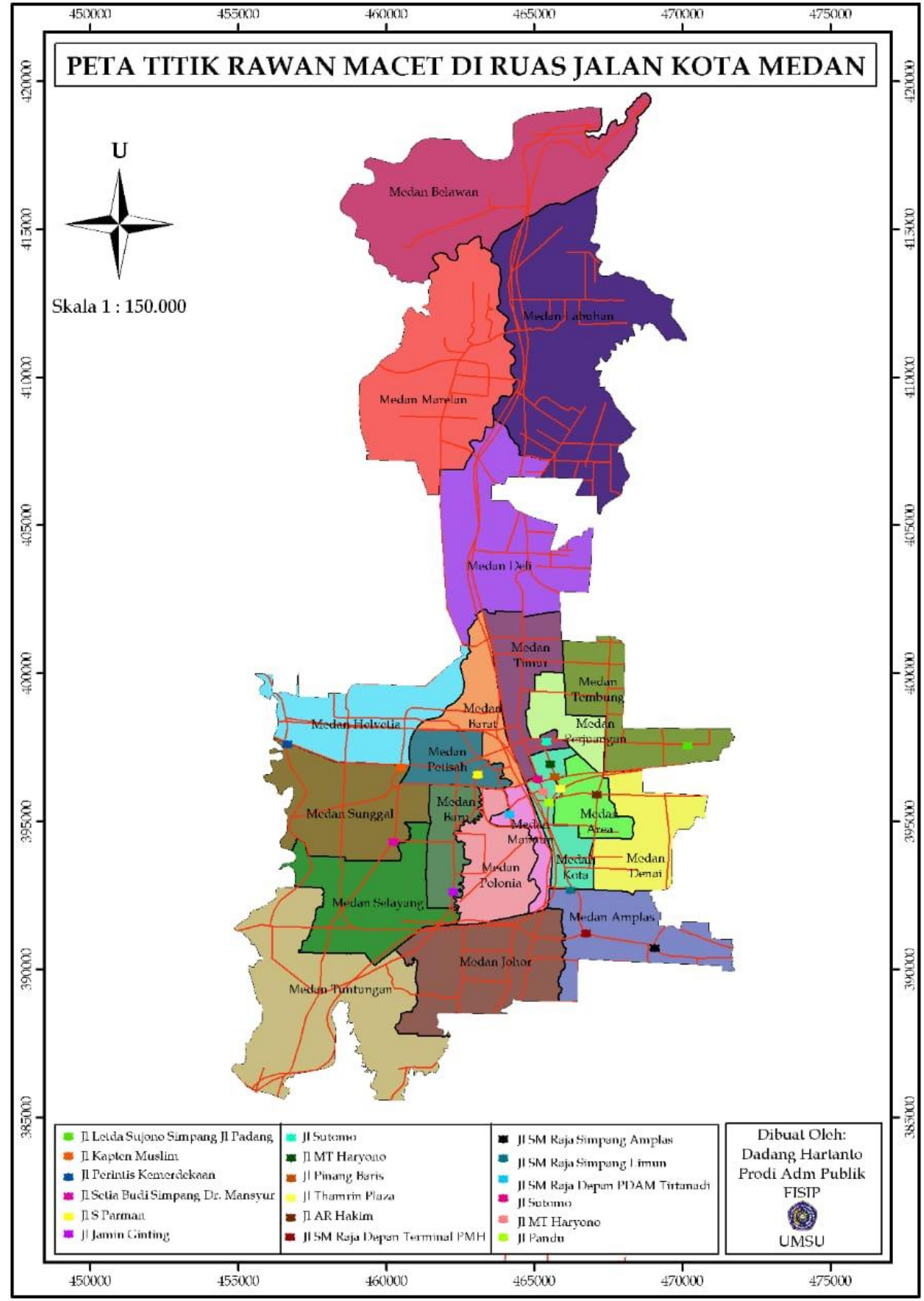

Gambar 2. Peta Potensi Kemacetan Berbasis SIG 


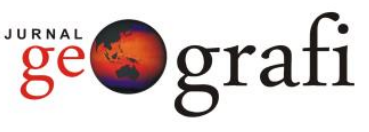

Berdasarkan Table 4 dan Gambar 2 diatas menunjukkan bahwa, beberapa titik jalan di wilayah Kota Medan rawan kemacetan. Wilayah yang memiliki level paling tinggi tingkat kemacetannya berada di wilayah Medan Kota dengan panjang jalan 123,4 $\mathrm{km}$. Penyebab kemacetan antara lain Jalan tersebut merupakan jalan utama, banyak terdapat pusat kegiatan seperti sekolah, industri, instansi perkantoran dan lainnya. Berdasarkan data pada Tabel 3 panjang jalannya sebesar 123,4 km.

\section{KESIMPULAN}

Fenomena kemacetan menyebabkan terhambatnya atau bahkan terhentinya lalu lintas yang disebabkan oleh banyaknya jumlah kendaraan melebihi kapasitas jalan. Kemacetan banyak terjadi terutama karena kurangnya moda transportasi publik atau sistem lalu lintas yang kurang baik atau memadai ataupun ketidakseimbangan seimbangnya kebutuhan jalan dengan kepadatan penduduk. Kemacetan lalu lintas menjadi permasalahan sehari-hari ditemukan di Pasar, Sekolah, Terminal bus, stasiun (seperti kejadian angkot ngetem sembarangan, kebakaran di pemukiman, dllDari pemetaan yang dilakukan wilayah yang paling rawan kemacetan terdapat di wilayah Medan Kota.

\section{DAFTAR PUSTAKA}

Badan Pusat Statistik. (2018). Sumatera Utara Dalam Angka 2018. Medan: BPS

Badan Pusat Statistik. (2018). Kota Medan Dalam Angka 2018. Medan: BPS

Cartwright, W. (2015). Mapping the world. International Journal of Cartography, 1 (10), 1-4

Badan Pusat Statistik. (2015). Kota Medan Dalam Angka 2015. Medan: BPS

Hartanto, D. \& Hidayat, N. (2019). Effect of Social Interaction Based on SocioReligions In Ensuring Security (Case Study: Capital City Police of Medan, Indonesia). Proceedings of the International Conference of
DOI: $10.24114 /$ ig.v12i01.16738

e-ISSN: 2549-7057 | p-ISSN: 2085-8167

Democratisation in Southeast Asia (ICDeSA 2019). Atlantis Press. https://doi.org/10.2991/icdesa19.2019.12

Mangatur, Edison dan Suandi. (2018). Analisis Dampak Kemacetan Lalu Lintas Terhadap Pendapatan Masyarakat dan Aksesibilitas Di Kota Jambi. Jurnal Pembangunan Berkelanjutan, 1 (1), 1-10

Munazar, et al. (2018). Dampak Sosial Ekonomi Pengguna Jalan Akibat Kemacetan Lalu Lintas Di Zero Point Kota Manado. Jurnal Pembanguan Ekonomi dan Keuangan Daerah,19 (7), 1-15

Susanti, S. dan Magdalena, M. (2015). Estimasi Biaya Kemacetan Di Kota Medan. Jurnal Penelitian Transportasi Multimoda,13 (1), 21 - 30

Vesilev, S.E. (2007). Who Is Who' On The Map. Cartographic Journal, 1 (1), 1-10 